\title{
The 2017 Summer Leadership Meetings
}

\author{
Brad Hokanson ${ }^{1}$
}

Published online: 24 May 2017

(C) Association for Educational Communications \& Technology 2017

During each summer, the Board of Directors and elected leadership of AECT gathers for the Summer Leadership Meeting. Most divisions are well represented and the value of personal engagement and interaction is clear. This year we are convening in Jacksonville, Florida, ahead of the November annual convention at the same location. A large part of the meeting deals with the operations of the organization, reviewing the budgets, hearing about growth plans, and discussing the evolution of the organization.

Part of each summer gathering also is devoted to the development of leadership skills for current and newer members of the board and those moving into leadership positions such as division president. For many, this may be their first step into an administrative or leadership position, providing valuable experience for an academic or professional career.

Each summer also includes substantial discussion of the current AECT Strategic Plan. As it is a continuous process,

Brad Hokanson

brad@umn.edu

1 University of Minnesota College of Design, Minneapolis, MN, USA the plan is renewed and revised each year, with contributions from many in the organization. This year, input was gathered through a series of focus groups by the Strategic Planning Committee chaired by AECT Past President Kay Persichitte. The current Strategic Plan is available online at http://aect.org (click on "Publications"). It is available to members and non-members.

This year we also are hosting a symposium for a brand new AECT journal, which will be published by Springer. The Journal of Formative Designs for Learning is designed to focus on publishing younger scholars on a broad range of topics. The journal publishes original papers on researchbased design and development in the field of teaching and learning. The focus is on applied research; the contents include evaluation reports, case studies, and lessons learned. Articles continue to be solicited through the AECT website. The symposium is occurring the weekend prior to the Summer Leadership Meetings and will be a gathering to develop articles for the journal. 